\title{
Comparative Antimicrobial Activities of a Consortium of Vernonia amygdalina and Amaranthus hybridus Extracts With Their CuO Nanoparticle Complexes
}

\author{
Mercy Oluwaseyi Bamigboye ${ }^{1 *}$, Risikat Nike Ahmed ${ }^{2}$ \\ ${ }^{1}$ Department of Industrial Chemistry, University of Ilorin, Ilorin Kwara State, Nigeria \\ ${ }^{2}$ Department of Microbiology, University of Ilorin, Ilorin Kwara State, Nigeria
}

Corresponding Author: Mercy Oluwaseyi Bamigboye, PhD, Department of Industrial Chemistry, University of Ilorin, Ilorin Kwara State Nigeria. Tel: +234-7033328218, Email: obaleye.mo@unilorin.edu.ng

Received September 11, 2018; Accepted January 20, 2019; Online Published March 15, 2019

\begin{abstract}
Introduction: The synthesis of nanoparticles from plant extracts has gained much attention in recent times. This study aimed at screening a consortium of crude extracts of Vernonia amygdalina and Amaranthus hybridus for antimicrobial activities.

Methods: The activities were compared with nanoparticles synthesized using the extracts. Powdered plant materials were separately suspended in distilled water and ethanol which were filtered to obtain crude extracts, while plant nanoparticles were synthesized by coupling with copper oxide $(\mathrm{CuO})$. Crude extracts were screened for the presence of bioactive constituents. Antibacterial assay was carried out by agar well diffusion, while the poisoned plate technique was used to determine antifungal activity.

Results: Plant extracts revealed the presence of alkaloids, steroids, saponins, and tannins. The aqueous crude extract produced higher activity than the ethanolic extract with the highest inhibition zone (29) against Bacillus megaterium at a concentration of $40 \mathrm{mg} / \mathrm{mL}$. Antifungal activity also showed that the aqueous extract was better than the ethanolic one. The aqueous nanoparticle extract was higher in antimicrobial activities compared to its crude counterpart, exhibiting inhibition zones of $34 \mathrm{~mm}$ at $40 \mathrm{mg} / \mathrm{mL}$ and $31 \mathrm{~mm}$ at $60 \mathrm{mg} / \mathrm{mL}$ for antibacterial and antifungal assays, respectively.

Conclusions: The results of this study indicate that aqueous extracts demonstrated higher antimicrobial activity than ethanolic ones, and the synthesis of nanoparticles using a consortium of 2 plants has the potential to enhance antimicrobial activity.

Keywords: Vernonia amygdalina, Amaranthus hybridus, Nanoparticles, Antimicrobial Activity, Synthesis

Citation: Bamigboye MO, Ahmed RN. Comparative antimicrobial activities of a consortium of Vernonia amygdalina and Amaranthus hybridus extracts with their CuO nanoparticle complexes. Int J Med Rev. 2019;6(1):31-34. doi:10.29252/JJMR-060107.
\end{abstract}

\section{Introduction}

The synthesis of complexes usually involves a top-down or bottom-up approach. In recent times, the attention of natural product scientists has drifted to the application of alternative medicines for the treatment and cure of infectious diseases. ${ }^{1}$ The plant kingdom has been exploited in this regard due to its production of a diverse array of bioactive phytochemicals. Vernonia amygdalina, commonly known as bitter leaf, is a plant that grows up to 3 meters high in Africa, especially in Nigeria. ${ }^{2}$ It has various health benefits, and extracts from it have been reported as very active against amoebic dysentery and gastrointestinal disorders with antimicrobial and antiparasitic activities. ${ }^{2}$ The phytoconstituents of this plant include saponins, tannins, alkaloids, and glycosides among others. ${ }^{3}$ The crude extracts of the leaves, stem bark, and roots are used as antimalarials and in treating eczema. Because of its antimalarial property, this plant is referred to as a quinine substitute. ${ }^{4}$ Amaranthus hybridus L. (English: Africa spinach), popularly called "Amaranth or pigweed," is an annual herbaceous plant growing 1-6 feet tall. It is a common species in cultivated fields and waste dump sites. Its rough and hairy leaves usually measure 3-6 inches long and have a dull green color. The plant possesses a taproot which is long and pink. A. hybridus has been shown to contain a variety of active principles which confer health benefits. ${ }^{5}$ The impact of a plant in the synthesis of complexes depends on the secondary metabolite. ${ }^{6}$ Several studies have reported the use of different plant extracts in the synthesis of nanoparticles. Such complexes often produce better antimicrobial activities against pathogenic organisms. ${ }^{7}$ Thus, the current research aimed to synthesize copper complex using a consortium of $V$. amygdalina and $A$. hybridus and to compare the antimicrobial activities of the nanoparticles with those of crude aqueous and ethanolic extracts of the plants.

\section{Methods}

Extract Preparation from Plants

The procedure followed by Shekhawat et $\mathrm{al}^{8}$ was adopted for

Copyright $\odot 2019$ The Author(s). This is an open-access article distributed under the terms of the Creative Commons Attribution License (http:// creativecommons.org/licenses/by/4.0), which permits unrestricted use, distribution, and reproduction in any medium, provided the original work is properly cited. 
this study. The plants were properly washed with distilled water, dried, and blended into small particles using a mortar and pestle. The powdered plant materials were suspended in distilled water and ethanol. The resulting filterate was dried in a dessicator.

Synthesis of Plant Nanoparticles With Copper Oxide A solution of copper oxide $(\mathrm{CuO})(1 \mathrm{mM})$ was prepared and mixed separately with aqueous and ethanolic extracts of the combination of $V$. amygdalina and A. hybridus. The solution was placed in a shaker at room temperature for 4 hours, decanted, and dried for further analysis following the procedure of Pirtarighat et al. ${ }^{9}$

Evaluation of Phytochemical Constituents of Plant Extracts The presence of the following plant constituents was determined following standard methods: alkaloids, steroids, tannins, and saponins. ${ }^{10}$

Test for Alkaloids: Five percent drop of $1 \mathrm{~mL}$ plant extract was mixed with $2 \mathrm{~mL}$ of $1 \% \mathrm{HCl}$ for 15 minutes. The mixture was allowed to cool, filtered, and 2 drops of picric acid were added to it. A cream precipitate was observed, indicating the presence of an alkaloid in the plant extract.

Test for steroids: A few drops of hydrogen tetraoxosulphate (VI) acid were mixed with $1 \mathrm{~mL}$ of the extracts. A clear red color was observed, indicating steroid in the extract.

Test for tannins: To the ethanolic and aqueous plant extracts, $7 \mathrm{~mL}$ of bromine water was added, and the bromine water was decolorized, indicating the presence of tannins.

Test for saponins: About $10 \mathrm{~mL}$ of distilled water was mixed thoroughly with the aqueous and ethanolic extracts in test tubes. The frothing was added to a few drops of olive oil; The appearance of foam indicated the presence of saponin.

Antimicrobial Activity of Plant Extracts and Nanoparticles Collection and Maintenance of Test Microorganisms

Pure clinical isolates of bacteria (Escherichia coli, Staphylococcus aureus, Pseudomonas aeruginosa, Bacillus subtilis, Bacillus megaterium, and Serratia marcescens) and fungi (Aspergillus niger, Candida albicans, and Penicillium chrysogenum) were obtained from the culture collection unit of the Department of Microbiology, University of Ilorin, Nigeria. They were routinely subcultured in appropriate agars for the purpose of purity and maintained at $4^{\circ} \mathrm{C}$ until further use.

\section{Antimicrobial Activities}

Antibacterial activity was carried out using the agar well diffusion assay described by Ahmed et al. ${ }^{11}$ The nutrient agar plate was inoculated with a 24 -hour old inoculum using sterile swab sticks. Wells measuring $5 \mathrm{~mm}$ were bored at the center of the inoculated plates. Extracts $(0.5 \mathrm{~mL})$ were introduced into the wells, the plates were incubated at $37^{\circ} \mathrm{C}$ for 24 hours, and the zone of inhibition was measured to the nearest millimeter. This was also done for C. albicans.

The poisoned plate technique was employed for the antifungal assay as described by Ahmed et al. ${ }^{12}$ A 24-48-hour old agar plate of each test fungus was prepared. Mycelial plugs from the advancing margins of these plates were cut using a cork borer and affixed at the center of a solidified sterile potato dextrose agar plate which had been previously cut open and its agar plug removed at the center. The plates were incubated at room temperature for 24-48 hours, and the radial growth was measured and recorded. Antibacterial and antifungal assays were done for both crude extracts and nanoparticles.

\section{Results}

The screening of aqueous and ethanolic extracts of the plant combination revealed that both extract types had the four assayed phytochemicals present as shown in Table 1 .

The antibacterial assay of the crude plant extracts revealed the aqueous extract to possess higher activity than the ethanolic extract. The highest activity $(29 \mathrm{~mm})$ was demonstrated at a concentration of $40 \mathrm{mg} / \mathrm{mL}$ against $B$. megaterium, while $11 \mathrm{~mm}$ was the highest activity shown by the ethanolic crude extract in the assay against $B$. subtilis and $S$. marcescens at 40 and $60 \mathrm{mg} / \mathrm{mL}$, respectively. The results are presented in Table 2.

Table 3 shows the sensitivity pattern of the test fungi to the crude extracts. It was observed that a similar trend with the antibacterial assay was obtained. The aqueous crude extract reduced mycelial growth of the test fungi better than the ethanolic extract, producing the highest antifungal effect (24 $\mathrm{mm}$ ) with the aqueous extract at a concentration of $60 \mathrm{mg} /$ $\mathrm{mL}$, while the ethanolic extract showed the highest activity $(19 \mathrm{~mm})$ at $20 \mathrm{mg} / \mathrm{mL}$.

The results of the antibacterial activity of nanoparticles synthesized from the combination of the 2 plants indicated that the aqueous extract was better in activity when compared with the ethanolic counterpart. The highest activity was shown to be $34 \mathrm{~mm}$ against $B$. megaterium (Table 4 ).

Table 5 shows the antifungal activity of the nanoparticles. According to the results, the aqueous extract exhibited the highest activity $(31 \mathrm{~mm})$, while $30 \mathrm{~mm}$ was recorded as the highest activity for the ethanolic nanoparticles.

\section{Discussion}

The phytochemical analyses of crude aqueous and ethanolic extracts of V. amygdalina and A. hybridus revealed the presence of alkaloids, steroids, saponins, and tannins. These groups of compounds may have been responsible for the antimicrobial activity demonstrated in the present study. According to previous research, it has been discovered that alcohol is used for extraction with most medicinal plants so as to obtain a

Table 1. Phytochemical Screening of Consortium of Vernonia amygdalina and Amaranthus hybridus Plant Extracts

\begin{tabular}{lll}
\hline Plant extract & Ethanol & Aqueous \\
\hline Alkaloid & + & + \\
Steroid & + & + \\
Saponin & + & + \\
Tannin & + & + \\
\hline Key: + Present. & &
\end{tabular}


Table 2. Antibacterial Activity of Vernonia amygdalina and Amaranthus hybridus Plant Extracts

\begin{tabular}{|c|c|c|c|c|c|c|c|c|}
\hline \multirow{2}{*}{ Plant Extract/Organisms } & \multicolumn{4}{|c|}{ Aqueous Extract $(\mathrm{mg} / \mathrm{mL})$} & \multicolumn{4}{|c|}{ Ethanolic Extract $(\mathrm{mg} / \mathrm{mL})$} \\
\hline & 20 & 40 & 60 & 80 & 20 & 40 & 60 & 80 \\
\hline Escherichia coli & 18 & 26 & 28 & 16 & 3 & 7 & 3 & 4 \\
\hline Staphylococcus aureus & 11 & 12 & 15 & 17 & 1 & 4 & 2 & 5 \\
\hline Pseudomonas aeruginosa & 10 & 12 & 11 & 15 & 3 & 2 & 1 & 7 \\
\hline Bacillus subtilis & 19 & 17 & 18 & 23 & 9 & 11 & 6 & 5 \\
\hline Bacillus megaterium & 23 & 29 & 15 & 10 & 7 & 4 & 9 & 4 \\
\hline Serratia marcescens & 15 & 12 & 20 & 15 & 9 & 7 & 11 & 5 \\
\hline
\end{tabular}

Table 3. Antifungal Activity of Vernonia amygdalina and Amaranthus hybridus Plant Extract

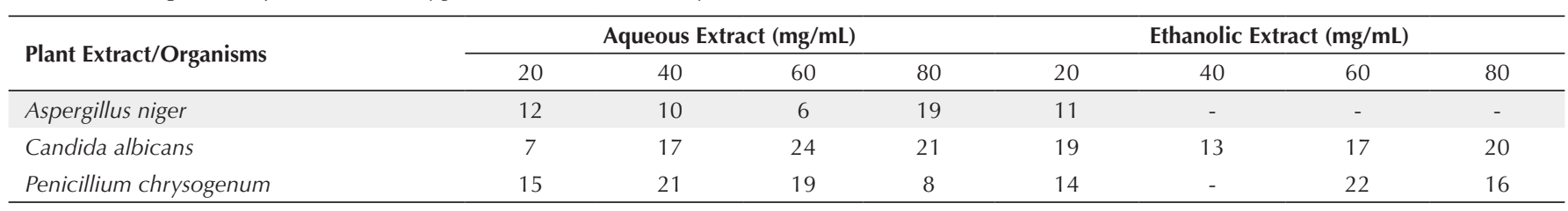

Table 4. Antibacterial Activity of Vernonia amygdalina and Amaranthus hybridus Nanoparticles

\begin{tabular}{|c|c|c|c|c|c|c|c|c|}
\hline \multirow{2}{*}{ Plant Extract/Organisms } & \multicolumn{4}{|c|}{ Aqueous Extract $(\mathrm{mg} / \mathrm{mL})$} & \multicolumn{4}{|c|}{ Ethanolic Extract $(\mathrm{mg} / \mathrm{mL})$} \\
\hline & 20 & 40 & 60 & 80 & 20 & 40 & 60 & 80 \\
\hline Escherichia coli & 23 & 21 & 17 & 11 & 23 & 18 & 13 & 17 \\
\hline Pseudomonas aeruginosa & - & 6 & 27 & 4 & 10 & 15 & 14 & 22 \\
\hline Bacillus subtilis & 14 & 25 & 17 & 22 & 14 & 26 & 18 & 13 \\
\hline Bacillus megaterium & 26 & 34 & 23 & 16 & 4 & 19 & 27 & 16 \\
\hline Serratia marcescens & 7 & 25 & 21 & 11 & 17 & 10 & 6 & 14 \\
\hline
\end{tabular}

Table 5. Antifungal Activity of Vernonia amygdalina and Amaranthus hybridus Nanoparticles

\begin{tabular}{|c|c|c|c|c|c|c|c|c|}
\hline \multirow{2}{*}{ Plant Extract/Organisms } & \multicolumn{4}{|c|}{ Aqueous Extract $(\mathrm{mg} / \mathrm{mL})$} & \multicolumn{4}{|c|}{ Ethanolic Extract $(\mathrm{mg} / \mathrm{mL})$} \\
\hline & 20 & 40 & 60 & 80 & 20 & 40 & 60 & 80 \\
\hline Aspergillus niger & 19 & 12 & 14 & 24 & 27 & 16 & 14 & 16 \\
\hline Candida albicans & 23 & 2 & 31 & 27 & 13 & 19 & 27 & 18 \\
\hline Penicillium chrysogenum & 16 & 24 & 15 & 16 & 18 & 14 & 30 & 13 \\
\hline
\end{tabular}

pure and effective compound. ${ }^{13}$ Plant extract contains its components, such as saponin, alkaloid, etc. From previous work, it was seen that the antimicrobial activities of some medicinal plants are being studied globally. It has also been reported that about $80 \%$ of plant extracts are used as herbal drugs worldwide. ${ }^{14}$ Mabhiza et al ${ }^{15}$ studied the antibacterial properties of alkaloid extracts from Callistemon citrinus and Vernonia adoensis against $S$. aureus and P. aeruginosa and showed the antibacterial activity as well as the inhibition of ATP-dependent transports of compounds through the microbial cell membranes. Steroids have been known to display broad spectrum antibacterial activity. Saponins are detergent-like substances exhibiting antibacterial activity. Tannins may work like a siderophore to coordinate iron from the medium and make iron not available to the organisms.

Table 2 indicates the antibacterial activity of mixed $V$. amygdalina and A. hybridus at different concentrations against the organisms. The aqueous extract of the mixed plants was observed to be more effective than the ethanolic extract against the organisms as shown by the zone of inhibition on the nutrient agar plates. Thus, the activities of the extract from the present study justifies the local use of the 2 plants in folkloric medicine. The observed activity demonstrated by the aqueous extract of the plants may be owing to the polarity of water. Water is a universal, highly polar solvent that can solubilize a wide range of polar phytoconstituents, thus aiding their extraction. This is in line with Ahmed et $\mathrm{al}^{11}{ }^{11}$ who reported water as an effective solvent for the extraction of plant secondary metabolites. Antibacterial and antifungal assays revealed that the crude extracts (aqueous and ethanolic) of the 2 plants were effective against all the test isolates except for Aspergillus niger which exhibited resistance to the ethanolic crude extracts of the plants. In the literature, it has been established that $A$. niger possesses a number of virulent factors which contribute to its pathogenicity. Several metabolites secreted by $A$. niger interfere with phagocytosis and opsonization. Moreover, Aspergillus species can bind specifically to different host tissue components, while their toxins give a general and significant immunosuppressive effect on host defenses. ${ }^{16}$ These may have been accountable for the 
resistance demonstrated by $A$. niger in this study. According to results from the antifungal assay of the nanoparticles, there was remarkable sensitivity against $A$. niger. This could be attributed to the incorporation of the metal oxides $(\mathrm{CuO})$ in the complex. In the literature, activity demonstrated by plant nanoparticles is due to their high surface-to-volume ratio which makes them highly reactive. This is in line with Prabhu and Poulose,${ }^{17}$ who reported nanoparticles as being able to adhere to the microbial cell wall and penetrate it, subsequently disrupting membrane integrity. ${ }^{18}$ Furthermore, these complexes possess the ability to pass through the membranes of microbial cells, ${ }^{19}$ thereby gaining access to target cells.

\section{Conclusions}

It has been shown that the plant extracts of $V$. amygdalina and A. hybridus have been synthesized with $\mathrm{CuO}$ nanoparticles which exhibit antimicrobial properties. The aqueous extracts were observed to have higher antimicrobial activity than the ethanolic extracts. The synthesis of the nanoparticles of the 2 plants could enhance the antimicrobial effectiveness.

\section{Authors' Contributions}

MOB did the synthesis of the plant extract nanoparticles complexes while the biological activities were carried out by RNA.

\section{Conflict of Interest Disclosures}

The authors declare they have no conflicts of interest.

\section{References}

1. Aruoma OI, Sun B, Fujii H, et al. Low molecular proanthocyanidin dietary biofactor Oligonol: Its modulation of oxidative stress, bioefficacy, neuroprotection, food application and chemoprevention potentials. Biofactors. 2006;27(1-4):245-265. doi:10.1002/biof.5520270121.

2. Kupchan SM, Hemingway RJ, Karim A, Werner D. Tumor inhibitors. XLVII. Vernodalin and vernomygdin, two new cytotoxic sesquiterpene lactones from Vernonia amygdalina Del. J Org Chem. 1969;34(12):3908-3911. doi:10.1021/jo01264a035.

3. Muraina IA, Adaudi AO, Mamman M, et al. Antimycoplasmal activity of some plant species from northern Nigeria compared to the currently used therapeutic agent. Pharm Biol. 2010;48(10):11031107. doi:10.3109/13880200903505633.

4. Challand S, Willcox M. A clinical trial of the traditional medicine Vernonia amygdalina in the treatment of uncomplicated malaria. J Altern Complement Med. 2009;15(11):1231-1237. doi:10.1089/ acm.2009.0098.

5. Ajaiyeoba EO, Onocha PA, Nwozo SO, Sama W. Antimicrobial and cytotoxicity evaluation of Buchholzia coriacea stem bark. Fitoterapia. 2003;74(7-8):706-709. doi:10.1016/S0367326X(03)00142-4.

6. He HP, Corke H. Oil and squalene in amaranthus grain and leaf. J Agric Food Chem. 2003;51(27):7913-7920. doi:10.1021/ jf030489q

7. Udochukwu U, Omeje FI, Uloma IS, Oseiwe FD. Phytochemical analysis of Vernonia amygdalina and Ocimum gratissimum extracts and their antibacterial activity on some drug resistant bacteria. Am J Res Commun. 2015;3(5):225-235.

8. Shekhawat MS, Manokari M, Kannan N, Revathi J, Latha R. Synthesis of silver nanoparticles using Cardiospermum halicacabum L. leaf extract and their characterization. J Phytopharmacol. 2013;2(5):1520.

9. Pirtarighat S, Ghannadnia M, Baghshahi S. Green synthesis of silver nanoparticles using the plant extract of Salvia spinosa grown in vitro and their antibacterial activity assessment. J Nanostructure Chem. 2019;9(1):1-9. doi:10.1007/s40097-018-0291-4.

10. Chanda S, Dave R. In vitro models for antioxidant activity evaluation and some medicinal plants possessing antioxidant properties: An overview. Afr J Microbiol Res. 2009;3(13):981-996.

11. Ahmed RN, Sani A, Ajiboye AE, Gambari-Ambali RO, Ezekiel Ku. Sensitivity of three gastro-intestinal organisms to aqueous extract of leaf of Ocimum gratissimum. Nigeria Journal of Pure and Applied Sciences. 2013;26:2460-2469.

12. Ahmed RN, Sani A, Igunnugbemi OO. Antifungal profiles of extracts of Vitellaria paradoxa (Shea-Butter) bark. Ethnobotanical leaflets. 2009;13:679-688.

13. Pal S, Tak YK, Song JM. Does the antibacterial activity of silver nanoparticles depend on the shape of the nanoparticle? A study of the Gram-negative bacterium Escherichia coli. Appl Environ Microbiol. 2007;73(6):1712-1720. doi:10.1128/aem.02218-06.

14. Blanco JG, Gil RR, Bocco JL, Meragelman TL, Genti-Raimondi S, Flury A. Aromatase inhibition by an 11,13-dihydroderivative of a sesquiterpene lactone. J Pharmacol Exp Ther. 2001;297(3):10991105.

15. Mabhiza D, Chitemerere T, Mukanganyama S. Antibacterial Properties of Alkaloid Extracts from Callistemon citrinus and Vernonia adoensis against Staphylococcus aureus and Pseudomonas aeruginosa. Int J Med Chem. 2016;2016:6304163. doi:10.1155/2016/6304163.

16. Tomee JF, Kauffman HF. Putative virulence factors of Aspergillus fumigatus. Clin Exp Allergy. 2000;30(4):476-484. doi:10.1046/ j.1365-2222.2000.00796.x.

17. Prabhu S, Poulose EK. Silver nanoparticles: mechanism of antimicrobial action, synthesis, medical applications, and toxicity effects. Int Nano Lett. 2012;2(1):32. doi:10.1186/2228-5326-2-32.

18. Parekh J, Chanda S. In vitro antibacterial activity of the crude methanol extract of Woodfordia fruticosa Kurz. Flower (Lythraceae). Braz J Microbial. 2007;38(2):204-207. doi:10.1590/ S1517-83822007000200004.

19. Suleiman $M N$. The in vitro phytochemical investigation on five medicinal plants in Anyigba and its environs, Kogi State, Nigeria. Der Pharmalia Sinica. 2011;2(4):108-111. 